\title{
On the modulation of the periodicity of the Faroe Bank Channel overflow instabilities
}

\author{
E. Darelius ${ }^{1}$, I. Fer ${ }^{1}$, T. Rasmussen ${ }^{2}$, C. Guo ${ }^{1}$, and K. M. H. Larsen ${ }^{3}$ \\ ${ }^{1}$ Geophysical Institute, University of Bergen and Bjerknes Centre for Climate Research, Bergen, Norway \\ ${ }^{2}$ Danish Meteorological Institute, Copenhagen, Denmark \\ ${ }^{3}$ Havstovan, Torshavn, Faroe Islands \\ Correspondence to: E. Darelius (elin.darelius@uib.no)
}

Received: 7 April 2015 - Published in Ocean Sci. Discuss.: 21 May 2015

Revised: 24 September 2015 - Accepted: 15 October 2015 - Published: 26 October 2015

\begin{abstract}
The Faroe Bank Channel (FBC) is one of the major pathways where dense, cold water formed in the Nordic Seas flows southward as a bottom-attached energetic plume towards the North Atlantic. The plume region downstream of the FBC sill is characterized by high mesoscale variability, quasi-regular oscillations and intense mixing. Here, 1 year long time series of velocity and temperature from ten moorings deployed in May 2012 in the plume region are analysed to describe variability in the strength and period of the oscillations. The eddy kinetic energy (EKE) associated with the oscillations changes by a factor of 10 during the year and the dominant period of the oscillations is modulated and varies between 3 to 4 and 6 days, where the shorter-period oscillations are more energetic. The dense water is observed on a wider portion of the slope (both deeper and shallower) during periods with energetic, short-period oscillations. The observations are complemented by results from a regional, high-resolution model that shows a similar variability in EKE and a gradual change in oscillation period of between 3 and 4 days. The observed variability in oscillation period is directly linked to changes in the volume transport across the sill: the oscillation period increases from approximately 3 days to about 6 days when the transport decreases from 2.4 to 1.9 Sv. A similar relation is obtained from the model. This is in agreement with results from a linear baroclinic instability analysis, which suggests that the period increases while the growth rate decreases for decreased plume thickness. Advective effects, caused by the variable background current, further modulate the observed periodicity by up to 1 day. In addition, it is shown that about $50 \%$ of the transport variability
\end{abstract}

across the sill is explained by changes in the local sea surface height gradient.

\section{Introduction}

The Faroe Bank Channel (FBC) is the deepest connection between the Nordic Seas and the North Atlantic, and it carries an overflow of about $2 \mathrm{~Sv}\left(1 \mathrm{~Sv}=10^{6} \mathrm{~m}^{3} \mathrm{~s}^{-1}\right)$ of cold, dense water formed north of the Greenland-Scotland ridge southwards (Hansen and Østerhus, 2007). Along its path, the overflowing water entrains and mixes with the overlying, ambient water (Mauritzen et al., 2005; Fer et al., 2010) and makes a substantial - up to $25 \%$ - contribution to the formation of North Atlantic Deep Water (Dickson and Brown, 1994).

Mooring records from the overflow plume region downstream of the FBC sill show energetic mesoscale variability; the dense water is observed to advance along the slope in $100-200 \mathrm{~m}$ thick domes with a periodicity of 2-6 days (Darelius et al., 2011; Geyer et al., 2006). The domes are associated with a velocity signal extending throughout the water column and have a signature in the sea surface height (Darelius et al., 2013; Høyer and Quadfasel, 2001). Recent modelling efforts suggest that the oscillations are caused by growing baroclinic instabilities at the plume interface, manifested as topographic Rossby waves in the upper layer (Guo et al., 2014).

Mesoscale oscillations are not uncommon on the continental slopes of the North Atlantic/Nordic Seas; Miller et al. (1996) report on barotropic oscillations with a period of 1.8 days further west $\left(12^{\circ} \mathrm{W}\right)$, on the southern side of the 
Iceland-Faroe Ridge, which they show to be wind-forced and linked to a resonant barotropic topographic Rossby normal mode. Further north, Mysak and Schott (1977) describe fluctuations in the Norwegian current with a periodicity of 2-3 days that they find to be caused by baroclinic instabilities. Skagseth and Orvik (2002) show that variability in the same frequency range (and the same region) agrees with topographic waves of the first mode, while slightly longer periods (3-5 days) correspond to the second mode.

Oscillations - hereafter referred to as eddies - similar to those observed in the FBC overflow are frequently observed in other overflow regions, e.g. the Denmark Strait overflow (Krauss and Käse, 1998) and the Filchner overflow in Antarctica (Darelius et al., 2009). The eddies modify vertical mixing and entrainment (Darelius et al., 2013; Ullgren et al., 2015), induce horizontal stirring (Voet and Quadfasel, 2010; Darelius et al., 2013) and influence the descent rate of the dense water (Seim et al., 2010). The intensity of eddy generation will thus affect the final properties and pathway of the overflow end product, the North Atlantic Deep Water.

Based on the first 1 year long mooring record covering the vertical and horizontal extents of the plume (Ullgren et al., 2015), the variability in eddy kinetic energy (EKE) and in the dominant periodicity associated with the eddies is described. The goal of the study is to investigate the observed modulation of the oscillations and its coupling to oceanic and atmospheric forcing. The mooring observations are combined with satellite observations of sea surface height anomalies and the analysis is extended to include results from a high-resolution regional model (Rasmussen et al., 2014). It is found that the observed variability in periodicity is directly linked to changes in volume transport across the sill, which in turn is strongly affected by the background flow.

\section{Data and methods}

\subsection{Moorings, 2012-2013}

Data were collected in the Faroe Bank Channel overflow region using eight bottom-anchored moorings in the period from 28 May 2012 to 5 June 2013 (Fig. 1). Three of the moorings were deployed in the channel (the C-array), and five on the open slope about $80 \mathrm{~km}$ downstream of the sill (the S-array and mooring M1). The moorings were equipped with temperature, conductivity and pressure recorders in addition to current meters. Further information on the moorings can be found in Ullgren et al. (2015) and in Table 1. The coordinate system for each mooring is aligned with the orientation of the corresponding mooring array, so that the $x$ axis is perpendicular to the array and the $y$ axis parallel to the array, pointing up-slope. The angle of rotation is 34 and $31^{\circ}$ (clockwise, from north) for the C- and S-array, respectively. Hourly mean data are interpolated to a grid with $1 \mathrm{~m}$ vertical resolution following the procedure outlined in Darelius et al.
(2011). Velocity data from periods when the instrument tilt exceeds the acceptable threshold given by the manufacturer are excluded from the analysis. This causes a slight bias towards lower velocities (since drag, and thus tilt, is larger for increasing velocities). The percentage of data discarded for any instrument is less than $3 \%$.

When the focus is on the evolution of the background field and not on the oscillations, the hourly data are filtered using a low-pass Butterworth filter of fourth order. The cut-off frequency is 30 days unless otherwise stated in the text where filtered data are discussed or shown.

Wavelet analysis is used to identify the dominant periods of variability and to describe how these change in time. The analysis is carried out using the hourly data and a Morlet mother function, and the $95 \%$ significance level is found using a regular chi square test (Torrence and Compo, 1997). Also, Paul and DOG (derivative of a Gaussian) mother functions were tried, but since the energy peaks appear narrower in time space and broader in spectral space (Torrence and Compo, 1997), they were found to be less informative. The dominant oscillation period is defined as the period with the highest significant energy level at each time step. The oscillations are seen throughout the water column (Darelius et al., 2013) and the wavelet analysis is carried out using data from levels well above the plume to avoid frictional effects within the interfacial/bottom boundary layer and spurious effects caused by the instrument moving in and out of the plume as the plume thickness changes.

The EKE associated with the oscillations is estimated by integration using

$\mathrm{EKE}=\int_{f_{1}}^{f_{2}}\left(\Theta_{u}+\Theta_{v}\right) \mathrm{d} f$,

where $f_{1}=1 / 8$ cycles per day (cpd), $f_{2}=2 / 5 \mathrm{cpd}$, and $\Theta_{u / v}$ is the spectral density of the velocities in the alongslope/across-slope direction, respectively. The presented EKE values are vertical means over the depth range with velocity measurements covering the entire deployment; see Table 1. The EKE values are artificially elevated at the plume interface, since an instrument at a given level shifts from being within (typically recording high velocities) and above (recording low velocities) the plume as the plume thickness changes throughout the oscillation period. This will affect the absolute value of the calculated EKE and the presented values are therefore normalized (with the maximum value obtained at each mooring site). It is assumed that the effect on the temporal evolution of the EKE is minor, as suggested by a comparison of time series calculated from $\mathrm{S} 3$ when including/excluding levels affected by the plume (not shown). Time series of EKE are obtained by first calculating $\Theta_{u / v}$ in 30 day long sliding windows. Integrating $\Theta_{v}$ separately gives $\mathrm{EKE}_{v}$, i.e. the EKE associated with motion in the across-slope direction. 
Table 1. Details of the moorings deployed from 28 May 2012 to 5 June 2013 downstream of the FBC sill. For instrumentation, the target height above bottom (in metres above bottom, mab) is given. RCM is the Aanderaa Recording Current Meter, SBE is Seabird, and $\mathrm{ADCP}$ is the acoustic Doppler current profiler. The interval given in the ADCP column shows the depth range (in mab) for which velocity measurements are obtained.

\begin{tabular}{rrrrrlr}
\hline & Longitude (W) & Latitude (N) & Depth (m) & RCM & SBE37 $1 / 39 / 56$ & ADCP \\
\hline C1 & $8^{\circ} 27.9^{\prime}$ & $61^{\circ} 40.43^{\prime}$ & 650 & - & $10 / 30 / 40 / 50 / 60 / 80$ & $20-200$ \\
& & & & & $100^{1} / 125 / 150 / 200^{1}$ & \\
C2 & $8^{\circ} 32.54^{\prime}$ & $61^{\circ} 37.4^{\prime}$ & 807 & $27^{4}$ & $25^{1} / 50 / 75 / 100^{1} / 125 / 150$ & $30-370$ \\
& & & & & $175 / 200 / 250^{1} / 300 / 350$ & \\
C3 & $8^{\circ} 37.7^{\prime}$ & $61^{\circ} 33.6^{\prime}$ & 859 & 25 & $27^{1} / 100^{1} / 140$ & $20-140$ \\
S1 & $9^{\circ} 28.98^{\prime}$ & $61^{\circ} 54.87^{\prime}$ & 610 & 80 & - & - \\
S2 & $9^{\circ} 36.54^{\prime}$ & $61^{\circ} 49.2^{\prime}$ & 805 & 25 & $27^{1} / 50 / 75 / 100^{1} / 150$ & $35-260$ \\
& & & & & $175 / 200^{1} / 250$ & \\
S3 & $9^{\circ} 43.22^{\prime}$ & $61^{\circ} 43.59^{\prime}$ & 950 & 25 & $27^{1} / 50 / 100^{1} / 125 / 150 / 200$ & $20-470$, \\
& & & & $250^{1} / 300 / 350 / 400 / 450 / 500^{1}$ & $520-820^{2}$ \\
S4 & $9^{\circ} 49.1^{\prime}$ & $61^{\circ} 38.89^{\prime}$ & 1082 & $25 / 75$ & $27^{1} 50 / 100^{1} / 125 / 175$ & - \\
& & & & $150 / 300$ & $250^{1} / 300 / 350 / 400 / 450 / 500^{1}$ & \\
M1 & $9^{\circ} 19.97^{\prime}$ & $61^{\circ} 45.01^{\prime}$ & 808 & 25 & $27^{1} / 50 / 75 / 100 / 125 / 150$ & $70-170^{3}$ \\
& & & & & $170^{1} / 200 / 250 / 300$ & \\
\hline
\end{tabular}

${ }^{1}$ Conductivity is measured; ${ }^{2}$ ADCP is upward looking; ${ }^{3}$ the record is only 3 months long; ${ }^{4}$ a Nortek Aquadopp is used.

The transport, $Q_{\mathrm{T}}$, of water colder than $T^{\circ} \mathrm{C}$ past a mooring array is estimated from

$Q_{\mathrm{T}}(t)=\sum_{i=1}^{n} \int_{0}^{z_{i, T(t)}} u_{i}(z, t) L_{i} \mathrm{~d} z$,

where $n$ is the number of moorings in the array, $u_{i}$ is the velocity perpendicular to the array at mooring $i, z_{i, T}$ the height of the $T^{\circ} \mathrm{C}$ isotherm at mooring $i$, and $L_{i}$ the representative width of the mooring. The distance between $\mathrm{C} 1$ and $\mathrm{C} 2$ is $7 \mathrm{~km}$ and the distance between $\mathrm{C} 2$ and $\mathrm{C} 3$ is $8 \mathrm{~km}$, and $L$ is taken to be 7, 7.5 and $8 \mathrm{~km}$ for $\mathrm{C} 1, \mathrm{C} 2$ and $\mathrm{C} 3$, respectively. The transport values given are calculated using $T=3^{\circ} \mathrm{C}$, which roughly corresponds to $\sigma_{\theta}=27.9 \mathrm{~kg} \mathrm{~m}^{-3}$ and density range 4-5 in Mauritzen et al. (2005). If $T=4$ or $T=6^{\circ} \mathrm{C}$ is chosen, the mean transport is increased by 10 and $27 \%$, respectively. The mooring array covers the extent of the plume relatively well, since the overflow is confined to the channel in the horizontal and the $3{ }^{\circ} \mathrm{C}$ isotherm is within the vertical extent of the moorings $100 / 99.8 / 73 \%$ of the time at $\mathrm{C} 1 / \mathrm{C} 2$ and $\mathrm{C} 3$. Transport calculations using the present data set and their sensitivity to the choice of parameters and methods are discussed in Ullgren et al. (2015).

\subsection{FBC-sill moorings}

The mooring records from the plume region in 20122013 described above are complemented with data from the long-term monitoring mooring from the FBC sill (Hansen and Østerhus, 2007). Moorings have been deployed quasicontinuously from 1995 until the present at the FB location on the FBC sill (see Fig. 1 for the location). Contemporary measurements from the sill (FB) and the plume region exist during the period June 2012-June 2013, when an upwardlooking ADCP (RD Instruments $75 \mathrm{kHz}$ BroadBand) was deployed at the FB.

The data from the FB consist of velocity profiles only, with no explicit information about the density of the overflowing water. Following the procedure outlined in Hansen and Østerhus (2007), the velocity profiles from the FB are used to calculate the "kinematic overflow" volume flux. The upper boundary of the overflow is then set to be the level where the velocity is half the maximum overflow velocity.

\subsection{Other data sets}

Meteorological data (wind, pressure and temperature) from the Danish Meteorological Institute (DMI) are available from a weather station in Torshavn, Faroe Islands (Cappelen, 2014), with a temporal resolution of $3 \mathrm{~h}$. Daily, gridded fields of sea level height anomalies (SLA) and geostrophic velocity anomalies calculated from satellite altimetry for the period and region of interest have been downloaded from http: //www.aviso.altimetry.fr. The altimeter products were produced by Ssalto/Duacs in collaboration with LOCEAN and $\mathrm{CTOH}$ and distributed by Aviso, with support from CNES.

\subsection{Numerical model}

The model is a slightly modified version of the HYbrid Coordinate Ocean Model (HYCOM) v2.2.18 (Bleck, 2002; Chassignet et al., 2007). HYCOM exploits a hybrid coordinate system that is isopycnal in the open, stratified ocean, but smoothly reverts to a terrain-following coordinate in shal- 


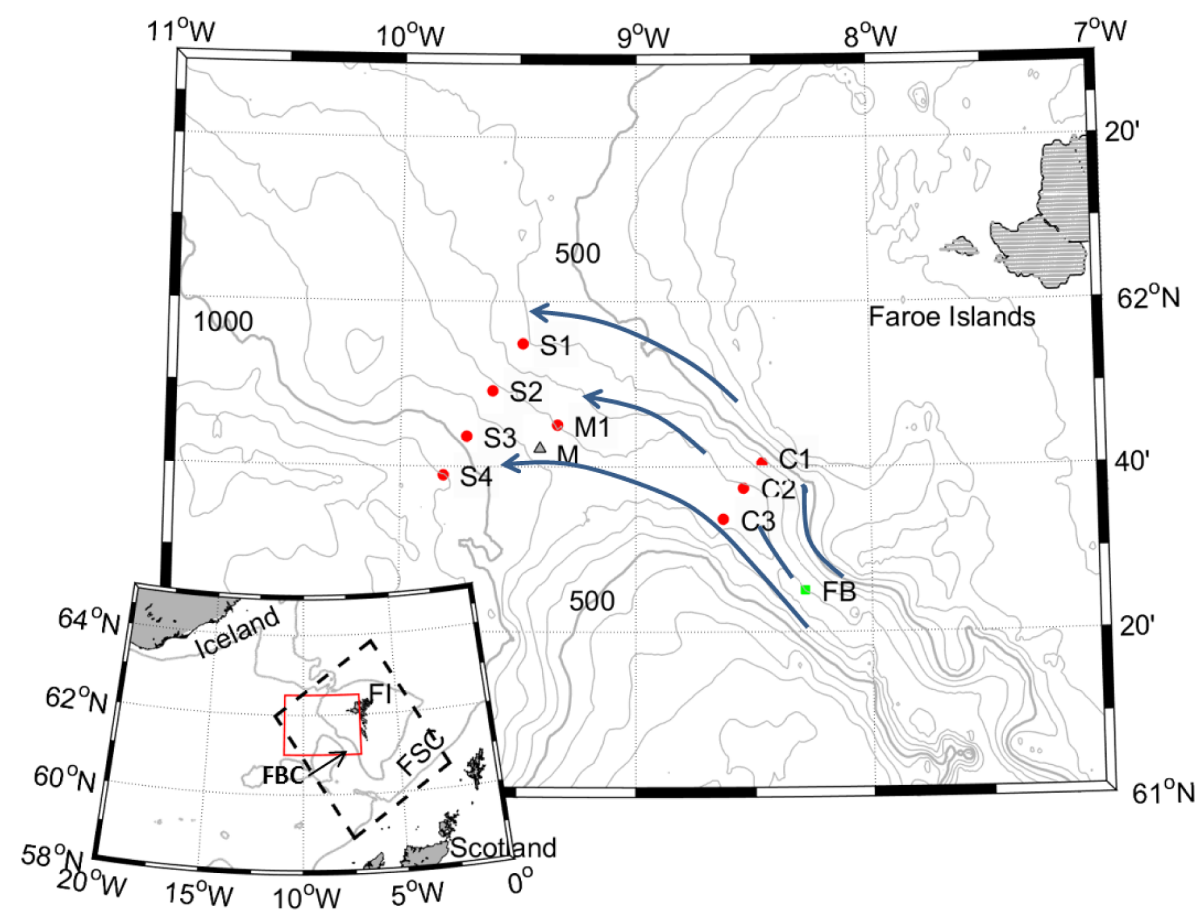

Figure 1. Map showing the study region. Isobaths are shown every $100 \mathrm{~m}$ (thin, grey lines) and every $500 \mathrm{~m}$ (thick, grey lines). The locations of the moorings are indicted by red labelled circles (Ullgren et al., 2015) and green squares (Hansen and Østerhus, 2007), and the overflow is indicated by the blue arrows. The location of the virtual mooring "M" (extracted from the model) is shown by the grey triangle. The arrows indicate the path of the FBC overflow. The inset shows the model domain (dashed, black box) and the study area (red box). The $500 \mathrm{~m}$ isobaths are shown in grey. Place names are indicated as FBC - Faroe Bank Channel; FSC - Faroe Shetland Channel; and FI - Faroe Islands.

low coastal regions, and to $z$-level coordinates in the mixed layer and/or unstratified seas. The vertical mixing is defined by the K-profile parameterization (KPP scheme; Large et al., 1994). The horizontal grid size ranges from 750 to $1300 \mathrm{~m}$ and the resolution is highest near the Faroe Islands. This model set-up has 32 vertical layers, 340 grid points in the south-westerly/north-easterly direction, and 400 grid points in the south-easterly/north-westerly direction. The model domain is shown in Fig. 1. The bathymetry is extracted from ETOPO1 (Amante and Eakins, 2009) combined with measurements conducted by the Faroe Marine Research Institute (FAMRI) and the Faroese coastguard (Simonsen et al., 2002).

Initial fields and boundary conditions (barotropic and baroclinic velocities, salinity, temperature and sea surface height) are provided by a hindcast archive from the Danish Meterological Institute covering the Arctic and the North Atlantic Ocean with a resolution of $10 \mathrm{~km}$ (Ribergaard, 2012). The hindcast was spun up by repeating the 1999 forcing five times. The regional model was then run for the period 19992009. The atmospheric forcing is extracted from Era-Interim (Dee et al., 2011) and consists of the air temperature, shortand long-wave radiation, precipitation, wind stress and the atmospheric vapour mixing ratio. The forcing is prescribed with a temporal resolution of $3 \mathrm{~h}$ and a spatial resolution of $79 \mathrm{~km}$, which is interpolated to the model grid. Further de- tails can be found in Rasmussen et al. (2014). In addition to the model output fields, time series for detailed analysis are extracted from a virtual mooring " $\mathrm{M}$ " on the slope (see Fig. 1).

\section{Results}

\subsection{The FBC overflow plume}

The FBC, located between the Faroe Plateau (FP) in the north and the Faroe Bank (FB) in the south, is about $840 \mathrm{~m}$ deep and less than $15 \mathrm{~km}$ wide at the sill. Results from the numerical model (Fig. 2) are used to illustrate the description of the FBC overflow plume. In the channel, the overflow forms a $200 \mathrm{~m}$ thick cold layer leaning on the FP, with core velocities of the order of $1 \mathrm{~m} \mathrm{~s}^{-1}$ (Fig. 2a, e.g. Hansen and Østerhus, 2007; Hansen et al., 2001). The cold water continues to flow north-westward along the slope as a dense, gravity-driven plume that widens and thins as the channel opens up (Fig. 2b; Mauritzen et al., 2005). Downstream of the sill, baroclinic instabilities develop (Guo et al., 2014) and the dense plume breaks up into domes of cold water that are associated with eddies in the upper layer (Fig. 2c-d, Darelius et al., 2013). When baroclinic instabilities grow, mean potential energy is transformed to kinetic energy associated 

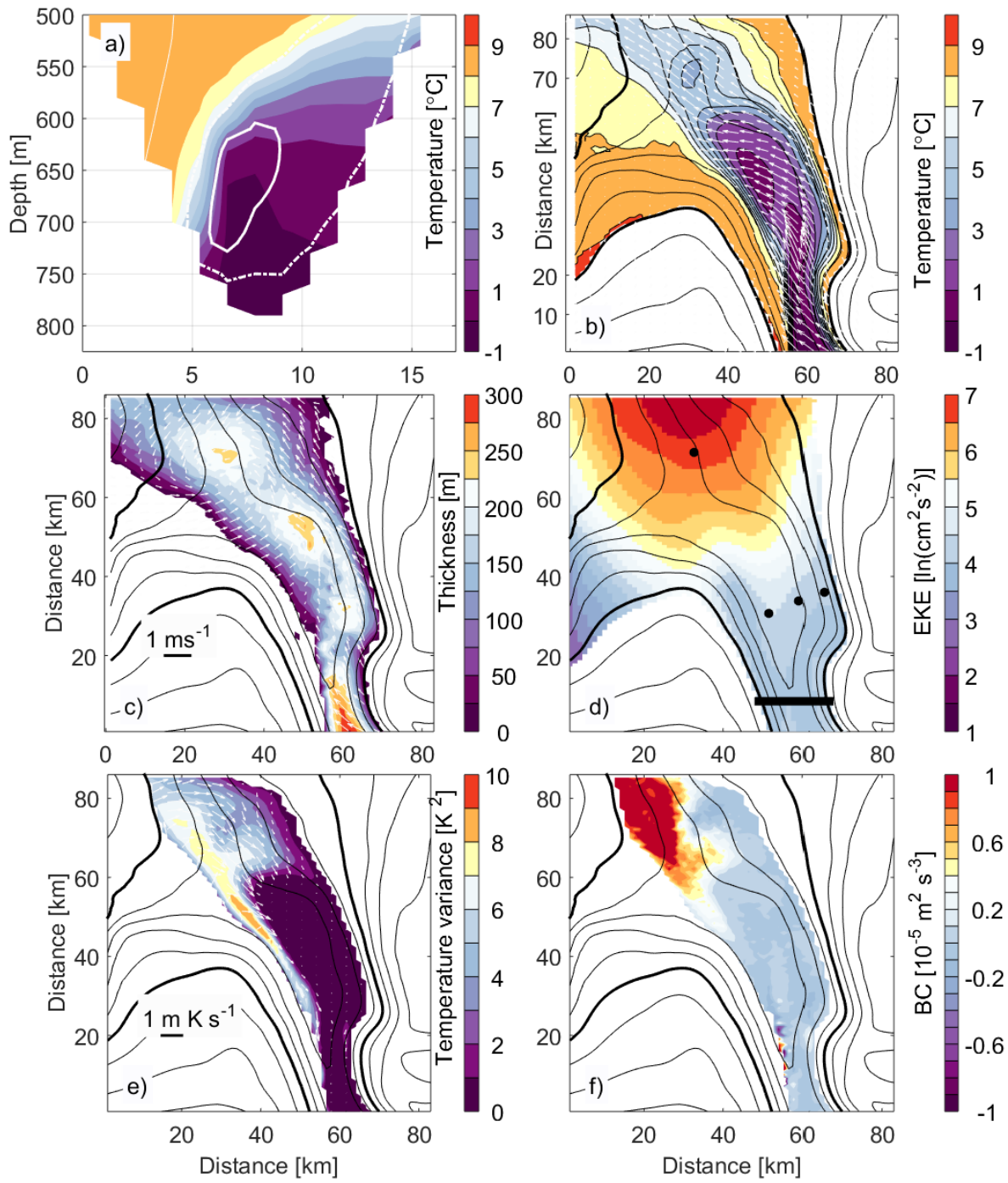

Figure 2. Modelled fields: (a) temperature (colour) and overflow velocity (white contours) at a section across the sill (thick black line in d). The $0 / 0.5 / 1 \mathrm{~m} \mathrm{~s}^{-1}$ contours are marked with a thin/dotted/thick white line. (b) Mean temperature (colour) and velocity at $100 \mathrm{mab}$ (white arrows). (c) Snapshot of plume thickness (colour) and velocity at $500 \mathrm{~m}$ depth from 10 August 2008 at 14:00 UTC. The velocity scale given by the thick black line is valid for panel (b-c). (d) Annual mean eddy kinetic energy (EKE, colour) at $300 \mathrm{~m}$ depth. Note that the colour scale is logarithmic. The thick black line indicates the position of the section shown in (a). (e) Temperature variance (colour) and divergent eddy heat flux (EHT, white arrows) at 100 mab. (f) Baroclinic conversion rate (BC, colour). In panels (b-f), the bathymetry is shown every $100 \mathrm{~m}$ (thin black lines), while the 500 and $1000 \mathrm{~m}$ isobaths are indicated by a thick black line. If not otherwise stated, the data shown are mean fields from August 2008. Only data from regions where the mean plume thickness is larger than $50 \mathrm{~m}$ are included in (e-f). For clarity, only data below $500 \mathrm{~m}$ depth are included in (b). The location of mooring C1-C3 and M is shown by black circles in (d).

with the eddies. The loss of available potential energy is associated with a downgradient transport of heat, which in the case of the FBC corresponds to an eddy heat flux (EHF) directed up-slope. Following the procedure outlined in Bishop et al. (2013) and Guo et al. (2014), the divergent EHF and the associated baroclinic conversion (BC) rate, which measures the rate of energy conversion from mean potential energy to eddy potential energy, are calculated using 1 month long subsets of the HYCOM model results. Figure 2e-f show examples of EHF and BC fields from August 2008, interpolated to
$100 \mathrm{~m}$ above bottom (mab; fields are calculated in horizontal layers every tenth metre in the vertical). The results are similar to those shown by Guo et al. (2014), with up-slope divergent eddy heat fluxes and high baroclinic conversion rates $\left(\mathrm{BC} \approx 10^{-5} \mathrm{~m}^{2} \mathrm{~s}^{-3}\right)$ appearing about $40-60 \mathrm{~km}$ downstream of the sill at the deeper edge of the dense plume. This indicates that the eddies in the model are caused by baroclinic instabilities. 

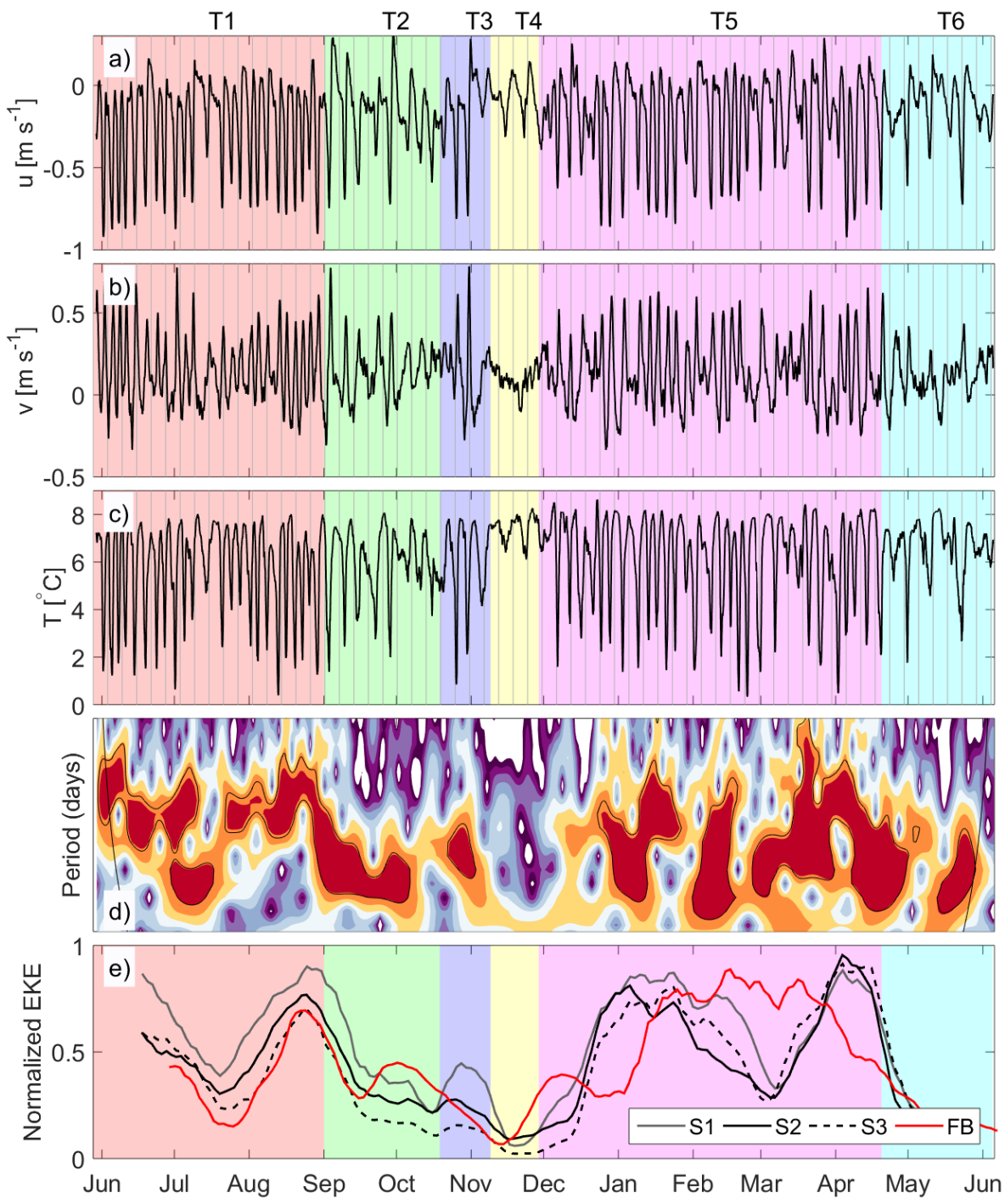

Figure 3. Time series from observations of (a) along-slope velocity, $u$, (b) across-slope velocity, $v$, and (c) temperature, $T$, measured at 80 mab at mooring S1. Thin grey lines are inserted every sixth day and the background colour identifies the time intervals $\mathrm{T}_{1}-\mathrm{T}_{6} \mathrm{marked}$ in (a) and discussed in the text. (d) Results from wavelet analysis of along-slope velocity, measured at 600 mab at mooring S3. Red colours indicate high energy levels and the black lines the $95 \%$ confidence levels. Results before and after the thin black lines at the start and end of the record are affected by edge effects. (e) Mean vertical EKE at moorings on the slope and the sill according to the legend. Values are normalized by the maximum value at each mooring.

Table 2. Definition of time intervals $\mathrm{T}_{1}-\mathrm{T}_{6}$. Dates are given in the format $\mathrm{dd} / \mathrm{mm} / \mathrm{yy}$.

\begin{tabular}{llr}
\hline & Interval & Duration (days) \\
\hline $\mathrm{T}_{1}$ & $01 / 06 / 12-01 / 09 / 12$ & 92 \\
$\mathrm{~T}_{2}$ & $02 / 09 / 12-19 / 10 / 12$ & 48 \\
$\mathrm{~T}_{3}$ & $20 / 10 / 12-09 / 11 / 12$ & 21 \\
$\mathrm{~T}_{4}$ & $10 / 11 / 12-29 / 11 / 12$ & 20 \\
$\mathrm{~T}_{5}$ & $30 / 11 / 12-20 / 04 / 13$ & 142 \\
$\mathrm{~T}_{6}$ & $21 / 04 / 12-05 / 06 / 13$ & 46 \\
\hline
\end{tabular}

\subsection{Temporal evolution of mesoscale variability on the slope}

The mooring records from the slope array show energetic oscillations in temperature and velocity with a period varying between 3 and 6 days (Fig. 3), similar to those described in Geyer et al. (2006) and Darelius et al. (2011, 2013). While Geyer et al. (2006) stated that the oscillations were "highly regular", the present, longer observation records show that the intensity and the periodicity of the oscillations vary considerably in time. A direct inspection of the velocity records and wavelet analysis (Fig. 3d) suggests that the periods of os- 


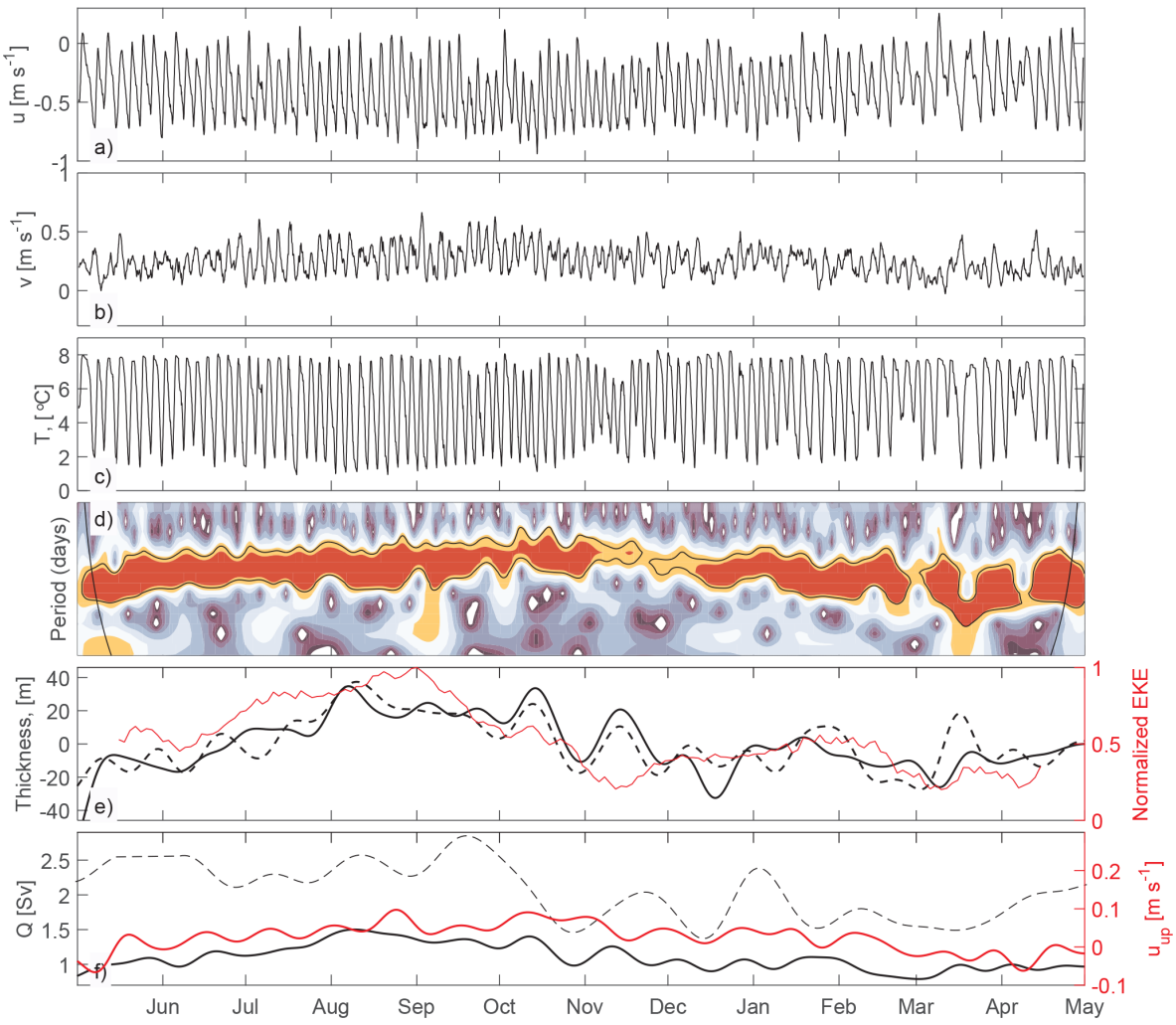

Figure 4. Modelled time series of (a) velocity, $u$, (b) velocity, $v$, and (c) temperature, $T$, at 100 mab at the virtual mooring $\mathrm{M}$ (see Fig. 1 for location). (d) Wavelet analysis of along-slope velocity at M, 600 mab. Red colours indicate high energy and the black line the $95 \%$ significance level. Results before and after the thin black lines at the start and end of the record are affected by edge effects. (e) Plume thickness anomaly at M (black line) and at the sill (black, dashed line) and vertical mean EKE from M, normalized by its maximum value. The plume thickness at $\mathrm{M}$ is scaled with a factor of 2. (f) Modelled (black line) and observed (black, dashed line) transport across the sill and modelled mean velocity in the along-slope direction in the upper layer (100-300 m) at M (red line).

Table 3. Plume and oscillation characteristics during $\mathrm{T}_{1}-\mathrm{T}_{6}$. Plume thickness is the mean height of the $6^{\circ} \mathrm{C}$ isotherm at $\mathrm{S} 2 \pm$ the standard deviation. Plume transport is the period mean transport obtained from FB. S1/S4 gives the percentage of time that the deepest instrument on the $\mathrm{S} 1$ and $\mathrm{S} 4$ mooring is surrounded by water colder than $3{ }^{\circ} \mathrm{C}$. Upper layer velocity is the along-slope velocity from $\mathrm{S} 3,700 \mathrm{mab} \pm$ the standard deviation of the low passed velocity records shown in Fig. 5c.

\begin{tabular}{rrrrrr}
\hline & $\begin{array}{r}\text { Oscillation } \\
\text { period (days) }\end{array}$ & $\begin{array}{r}\text { Plume } \\
\text { thickness }(\mathrm{m})\end{array}$ & $\begin{array}{r}\text { Plume } \\
\text { transport }(\mathrm{Sv})\end{array}$ & $\begin{array}{r}\text { S1/S4 } \\
(\%)\end{array}$ & $\begin{array}{r}\text { Upper layer } \\
\text { velocity }\left(\mathrm{cm} \mathrm{s}^{-1}\right)\end{array}$ \\
\hline $\mathrm{T}_{1}$ & $3-4$ & $108 \pm 39$ & 2.3 & $15 / 23$ & $1 \pm 1$ \\
$\mathrm{~T}_{2}$ & 6 & $102 \pm 29$ & 2.0 & $6 / 8$ & $-7 \pm 1$ \\
$\mathrm{~T}_{3}$ & 6 & $97 \pm 33$ & 1.9 & $7 / 1$ & $5 \pm 1$ \\
$\mathrm{~T}_{4}$ & - & $84 \pm 10$ & 1.5 & $0 / 0$ & $-3 \pm 0$ \\
$\mathrm{~T}_{5}$ & $3-4 / 6$ & $97 \pm 35$ & 2.2 & $11 / 26$ & $0 \pm 1$ \\
$\mathrm{~T}_{6}$ & $6 /-$ & $89 \pm 20$ & 1.7 & $2 / 1$ & $-2 \pm 0$ \\
\hline
\end{tabular}

cillations alternate between 3 and 4 days and 6 days, where the low-amplitude (i.e. less energetic) oscillations typically have longer periods. Based on the oscillation characteristics, the time series has been divided into six intervals, $\mathrm{T}_{1}-\mathrm{T}_{6}$ (see Tables 2-3 and Fig. 3). In all mooring locations, the EKE associated with the oscillations shows high values in August, January-February and in April, and a minimum in early win- ter (October-December, Fig. 3e). The intra-seasonal variability is large; for example, at S3 the November EKE is only $10 \%$ of the annual maximum value.

In the numerical model, the dominant periodicity of the oscillations is 3-4 days (Fig. $4 a-d$ ), similar to the observations. Unfortunately, a direct comparison is not possible because the model was not run for a period overlapping with 

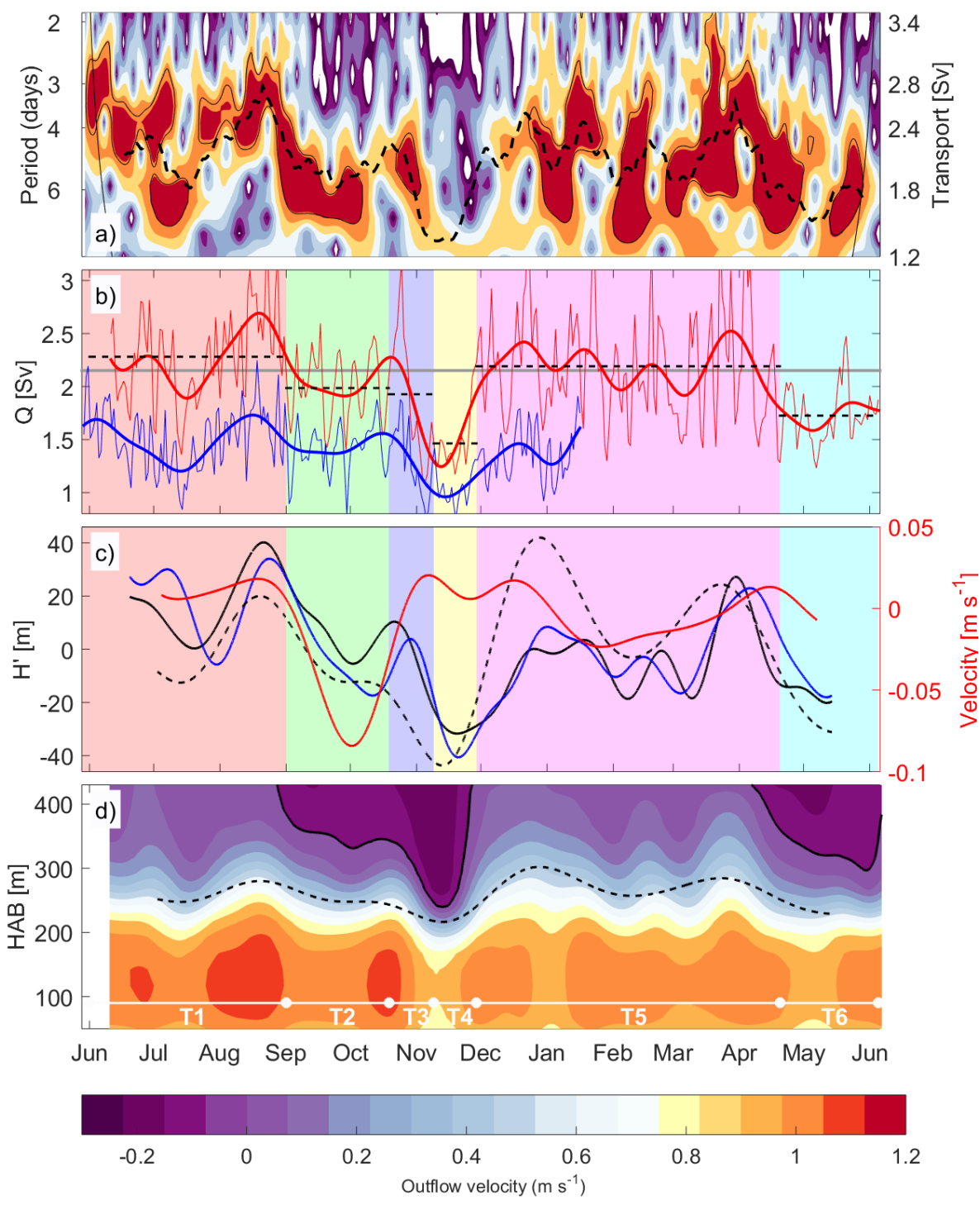

Figure 5. Time series from observations. (a) Results from the wavelet analysis of the along-slope velocity, S3 600 mab (same as Fig. 3d). Red colours indicate high energy levels and the black line the $95 \%$ confidence levels. The dashed line (right axis) is the transport estimate from the FB. (b) Transport estimates based on data from array $\mathrm{C}$ (blue) and the FB (red). Thin lines are daily means and thick lines show the low-passed time series. The dashed lines show mean values from the FB during time interval $\mathrm{T}_{1}-\mathrm{T}_{6}$ discussed in the text and indicated in the background by colours. The grey line shows the mean value from the sill for the period 1995-2005 (Hansen and Østerhus, 2007). (c) Plume thickness anomaly $\left(H^{\prime}=H-\bar{H}\right.$, where the bar denotes the time mean value) at S2 (blue), S3 (black, full) and FB (black, dashed) and upper layer (500-700 mab) velocity in the along-slope direction at S3 (red). The data are low pass filtered (30 days) and data from S2 to $\mathrm{S} 3$ are scaled with a factor of 2. Plume thickness is defined as the height above bottom of the $6{ }^{\circ} \mathrm{C}$ isotherm (S2-S3) and as the height where the velocity is half the maximum overflow velocity ("kinematic thickness", Hansen and Østerhus, 2007) at the FB. (d) Observed overflow velocity (low pass filtered, 30 days) at the FB in June 2012-May 2013, where positive values (red colours) indicate flow towards the North Atlantic (overflow). The black, full line shows the zero isotach and the dashed, black line the "kinematic" plume thickness. The white line intersected by white circles shows the time intervals introduced in Fig. 3 and discussed in the text.

the observations. The variability of the oscillations in the model, nevertheless, shows similarities to that in the observations: the EKE associated with the oscillations on the slope (at mooring $\mathrm{M}$ ) varies by a factor of 10 , with a minimum in March-April and a maximum in August-September (Fig. 4e). A comparison of Fig. 3d (observations) and Fig. 4d (model), however, shows that while the oscillations in the observations alternate between shorter (3-4-day) and longer (6day) periods, the change in period of the model oscillations is relatively gradual and appears to follow a seasonal cycle; it decreases from about 4 days in summer to about 3 days in November-December and then increases again to about 


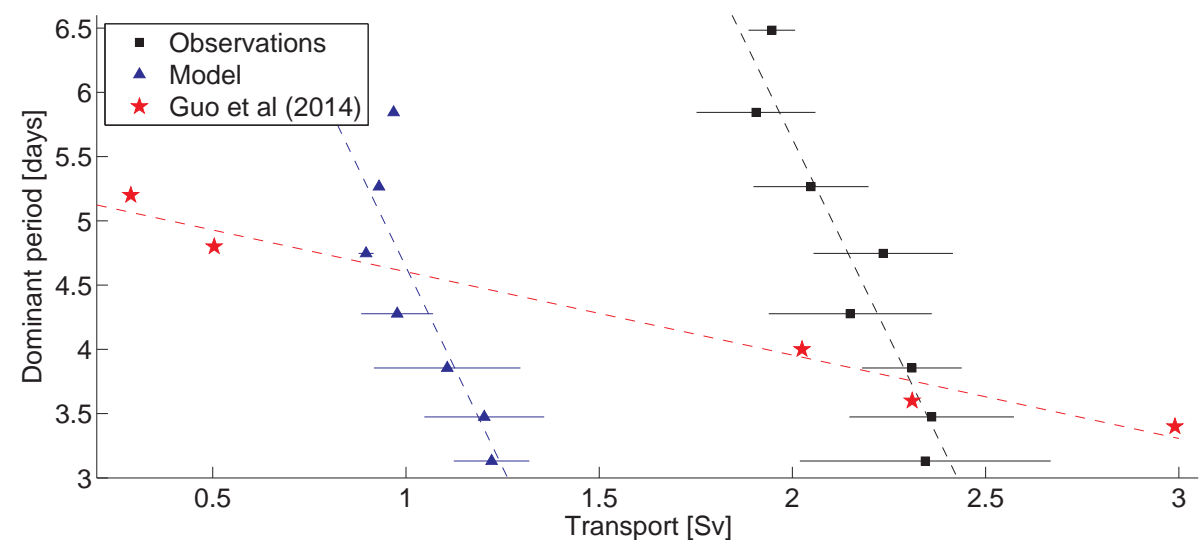

Figure 6. Mean transport across the sill averaged in time periods with different dominant oscillation periods approximately $80 \mathrm{~km}$ downstream of the sill. The dominant period is identified as the most energetic oscillation period for each time step in the wavelet analysis. The horizontal lines show the standard deviation and the dashed lines show the results from linear regression.

4 days towards the end of the record. Only once, in March, does the modelled oscillation period increase to about 6 days.

\subsection{Modulation by the overflow at the sill}

Time series of kinematic overflow measured at the FB are shown in Fig. $5 b$ together with the volume flux of water colder than $T=3{ }^{\circ} \mathrm{C}$ past array C (see Sect. 2.1 for calculation details). During the period with overlapping measurements, the low passed transport time series from the FB and array $\mathrm{C}$ correlate well with a correlation coefficient of 0.9 . The transport estimates from array $\mathrm{C}$ are lower by a factor of 0.66 compared with the kinematic overflow at the FB. As discussed in e.g. Hansen and Østerhus (2007), the transport across the sill shows considerable variability on both daily and monthly timescales. A relationship between the lowpassed (14-day) transport across the sill and the dominant period of the oscillations on the slope is apparent in Fig. 5a and further quantified in Fig. 6. Here, at each time step, the dominant oscillation period (i.e. the oscillation period with the highest significant energy level) from the wavelet analysis (shown in Figs. 3d and 5a) and the transport have been identified, and the transport is averaged in bins of oscillation period. Times of high transport coincide with shorter oscillation periods and times with low transport with longer oscillation periods. Linear regression gives a decrease in oscillation period of about 5.8 days $\mathrm{Sv}^{-1}$ for the observations.

The modelled transport $Q$ across the sill displays a seasonal signal, increasing from $1 \mathrm{~Sv}$ in summer to $1.5 \mathrm{~Sv}$ in autumn (Fig. 4f). The observations from 2012 to 2013 do not show a seasonal signal in transport; however, a seasonality (of about the same amplitude but shifted in time with respect to the numerical model) emerges when 10 years of data from FB are synthesized (Hansen and Østerhus, 2007, see their Fig. 23d). Repeating the analysis leading to the results shown in Fig. 6 using the model data gives a sensitivity similar to the observations $\left(-6.2\right.$ days $\left.\mathrm{Sv}^{-1}\right)$. The modelled transports, however, are approximately $1 \mathrm{~Sv}$ lower than the observations. Note that longer period oscillations are only found during one short interval in the modelled results.

The variability in (modelled and observed) transport is to some extent reflected in the plume thickness both at the sill and down-slope in the plume region (Figs. 5c and 4e); low transport values are typically associated with a thinner than normal plume, notably during $\mathrm{T}_{1}$ and $\mathrm{T}_{4}$. The plume thickness recorded at S2 and S3 typically vary in phase, implying that the variability is not caused by plume meandering. During periods with more intense oscillations and higher than normal plume thickness at $\mathrm{S} 2$ and $\mathrm{S} 3\left(\mathrm{~T}_{1}\right.$ and $\left.\mathrm{T}_{5}\right)$, cold plume water is more often than normal present at the upper (S1) and lower (S4) moorings in the array (see Table 3). During $\mathrm{T}_{4}$, temperatures recorded by these moorings are above $3{ }^{\circ} \mathrm{C}$ at all times.

\subsection{Currents in the upper layer}

The upper layer in the region is highly active and in this section it will be shown that changes in the upper layer circulation coincide with changes in the overflow and in the oscillations. The Faroe Islands are circumnavigated by current branches carrying warm Atlantic water northward (Hansen et al., 2003). Atlantic water enters the study region from the south-west, along the slope of the Faroe Bank towards the Faroe Bank Channel, and there is also a current along the Iceland-Faroe slope on the Faroe Plateau side that carries Atlantic water north-westward, feeding into the Faroe Current farther north (e.g. Larsen et al., 2012). The modelled upper layer velocities (300 $\mathrm{m}$ depth) are shown in Fig. 7 and agree with this circulation scheme. The clockwise circulation around the Faroe Bank and the north-westward flow on the Faroe Plateau side cause a relatively strong shear across the 

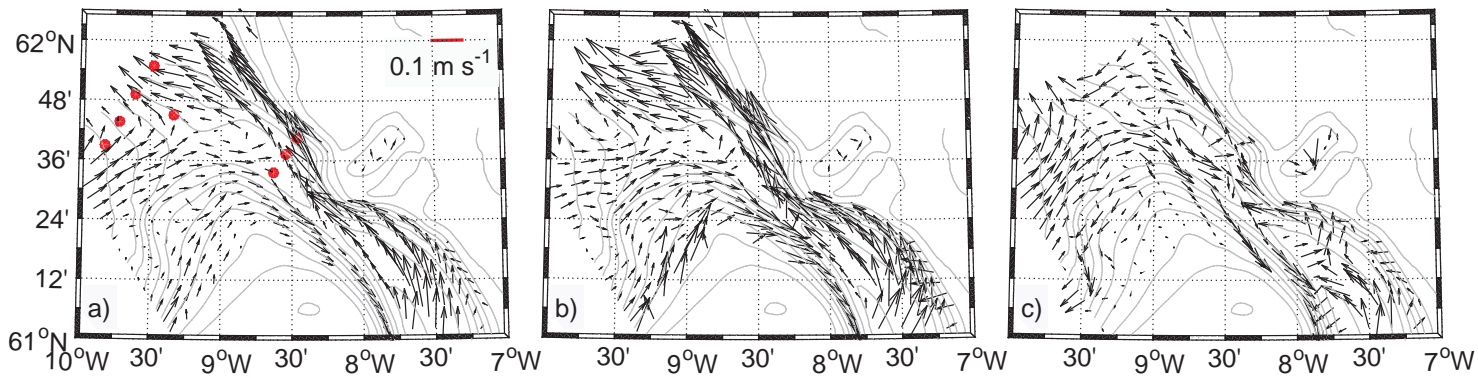

Figure 7. Modelled (a) annual mean currents and monthly mean currents in (b) August 2008 and (c) March 2009 at $300 \mathrm{~m}$ depth. Isobaths are shown every $100 \mathrm{~m}$ (grey, thin lines) and every $500 \mathrm{~m}$ (thick, grey line), and the circles indicate the mooring locations.
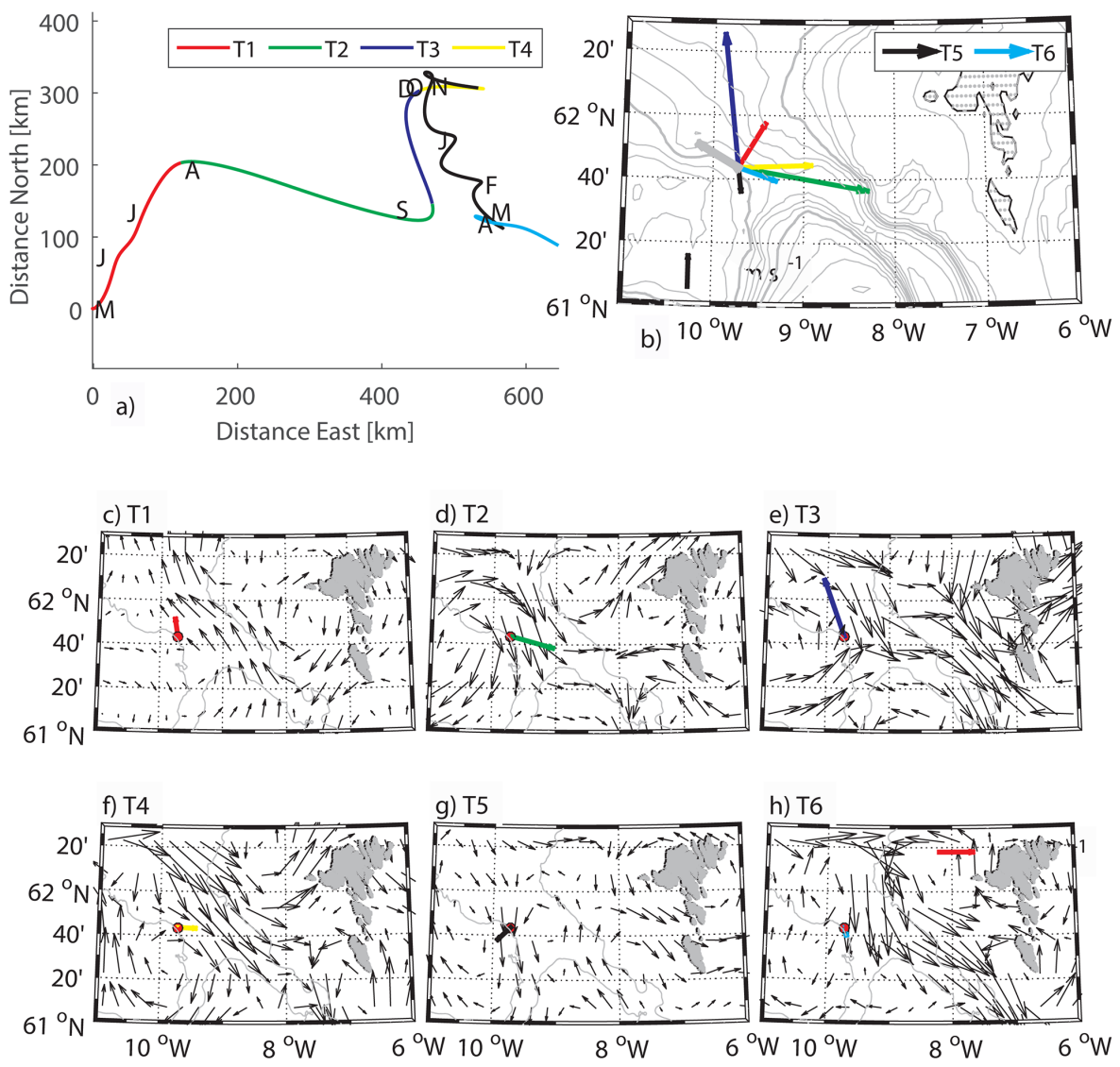

Figure 8. (a) Progressive vector diagram of upper layer velocity $\left(u_{\mathrm{up}}\right)$ from $\mathrm{S} 3$ with data from time intervals $\mathrm{T}_{1}-\mathrm{T}_{6}($ Table 2$)$ coloured according to the legend. (b) Mean velocity in the upper layer at $S 3$ during $T_{1}-T_{6}$. The velocity scale is given in the lower left corner and the grey arrow at $\mathrm{S} 3$ shows the mean direction of the dense plume, 75 mab. Data in (a-b) are vertical mean values from 150 to $500 \mathrm{~m}$ depth. Mean geostrophic velocity anomaly (AVISO) during (c) $\mathrm{T}_{1}$, (d) $\mathrm{T}_{2}$, (e) $\mathrm{T}_{3}$, (f) $\mathrm{T}_{4}$, (g) $\mathrm{T}_{5}$ and (h) $\mathrm{T}_{6}$. The mean upper layer velocity anomaly from $\mathrm{S} 3$ for each period is included for reference and the velocity scale (for $\mathbf{c}-\mathbf{h})$ is given in the lower right corner of (h) as a labelled red line. The location of S3 is marked with a red circle in $(\mathbf{c}-\mathbf{h})$.

FBC (a similar shear is observed in mooring data from the sill; Hansen and Østerhus, 2007).

Upper layer velocities are observed only at S3 and FB. While the deployment mean current at $\mathrm{S} 3$ is directed towards the FBC, the direction of the current is seen to change relatively abruptly. Figure 8 shows the observations from S3 as a progressive vector diagram together with the mean velocity vectors during $\mathrm{T}_{1}-\mathrm{T}_{6}$. The direction of the $u_{\text {up }}$ changes from north-eastward in $\mathrm{T}_{1}$ to south-eastward in $\mathrm{T}_{2}$ and northward in $T_{3}$. During intervals $T_{2}, T_{4}$ and $T_{6}$, the mean upper layer current has a component directed towards the sill (i.e. opposing the dense overflow). The intervals with sill-ward flow 

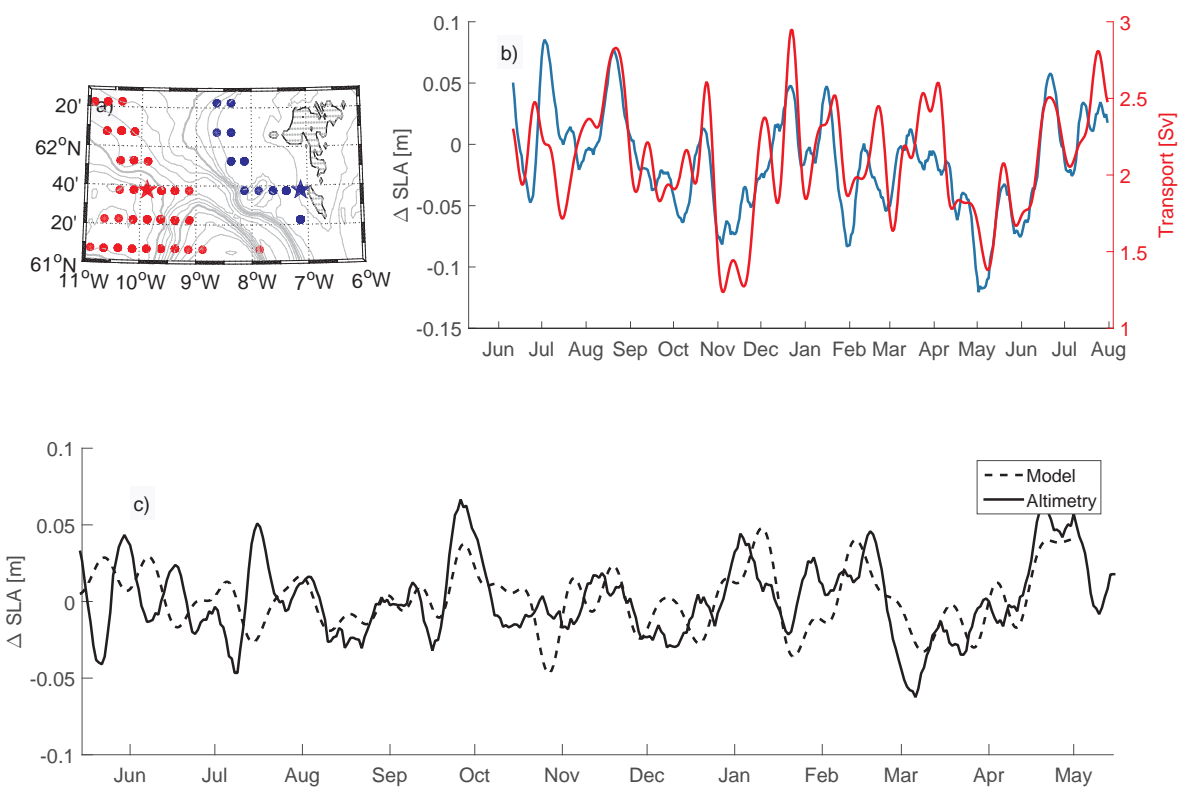

Figure 9. (a) Map over the study region showing the grid points from the AVISO gridded data set of sea level anomalies (SLA) from 2012 to 2013 where the difference in SLA ( $\triangle$ SLA) between any of the blue circles and (at least) one of the red circles correlates positively with the transport across the sill with a correlation coefficient $r>0.65$. The stars indicate the grid point combination with the highest correlation $(r=0.71)$ and the corresponding time series of $\triangle$ SLA is shown in (b, blue line) together with the transport across the sill from FB (red line). All data are 14-day low passed filtered. (c) $\triangle$ SLA between the points marked with a star in (a) from the numerical model (dashed, black line) and from AVISO (black line) in 2008-2009. The data are band passed (14-120 days).

are associated with anomalous inflow at the sill at depths shallower than 250-350 mab, and relatively weak overflow at FB (Fig. 5d). Geostrophic velocity anomalies calculated from satellite altimetry for the period and the region of interest are shown in Fig. 8c-h. Geostrophic current anomalies during $T_{2}, T_{4}$ and $T_{6}$ are directed towards the sill, in fair agreement with the observations from S3 and FB. Above the plume, the velocity profiles show little variability in the vertical, suggesting (together with the relatively large sea surface height (SSH) gradient derived from AVISO) that the upper layer current has a large barotropic component.

Inspection of Figs. 3, 5 and 8 suggests that low-amplitude, long-period or irregular oscillations occur when the mean upper layer current is sill-ward, while energetic, relatively regular and shorter-period oscillations occur when the mean upper layer current at S3 is transverse to the dense overflow. The properties of the oscillations and the plume during $\mathrm{T}_{1-}$ $\mathrm{T}_{6}$ are summarized in Table 3.

The modelled currents display less intra-seasonal variability but a clear seasonal signal where currents are stronger and extend further out from the shelf in autumn than in spring (Fig. 7b-c). At the virtual mooring M, for example, upperlayer along-slope velocity increases from virtually nil in the spring to $0.1 \mathrm{~m} \mathrm{~s}^{-1}$ in late autumn (Fig. $4 \mathrm{f}$ ). The seasonality in the upper layer aligns with the variability in overflow transport and oscillation period: the seasonal extrema in transport, upper-layer velocity and oscillation period coincide.

\subsection{Barotropic forcing of the FBC overflow}

The results presented in Sect. 3.4 suggest that the overflow transport variability on intra-seasonal timescales is partly determined by the background flow, which has a large barotropic component. We therefore seek a relationship between the overflow transport and local SSH - gradients forcing a barotropic, background current.

Figure 9a shows the combinations of grid points from the AVISO gridded sea level anomaly (SLA) data set, for which the correlation coefficient between sea level difference $\triangle$ SLA and the transport across the FBC sill is greater than $r=0.65$. All possible combinations of grid points within the area shown have been tested. High transport values coincide with high SLA on the Faroe Plateau and low SLA above the slope, i.e. with a geostrophically balanced barotropic current aligned with the slope and the dense overflow. The time series of $\triangle$ SLA between the combination of grid points giving the highest correlation with the transport is shown in Fig. 9b. The maximum correlation found is $r=0.71$, giving a squared correlation of $r^{2}=0.50$ which indicates that about $50 \%$ of the variance can be explained by the local gradients in $\mathrm{SSH}$. 

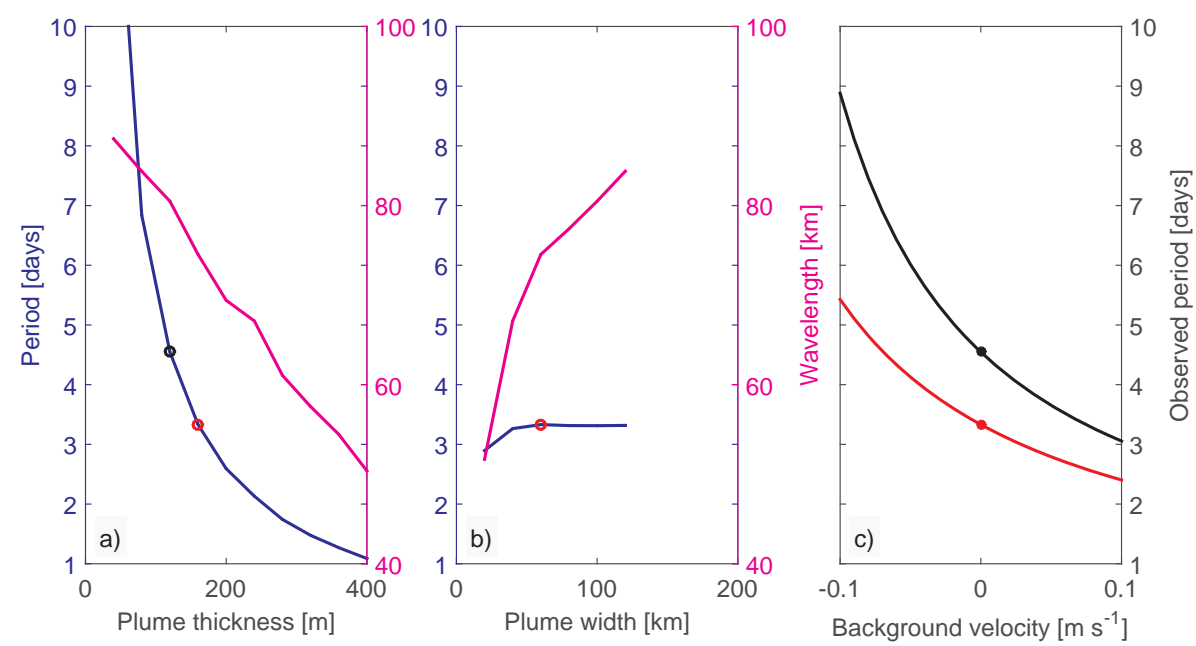

Figure 10. Period (blue) and wavelength (magenta) of the most unstable wave as a function of (a) plume thickness (plume width is $60 \mathrm{~km}$ ) and (b) plume width (plume thickness is $160 \mathrm{~m}$ ). (c) Period observed at a stationary mooring as a function of background velocity for an oscillation with an intrinsic period and a wavelength of 3.33/4.5 days and 75/80 km (red/black line). The corresponding period-wavelength pairs are marked with circles in the same colour in $(\mathbf{a}-\mathbf{b})$.

The variability in $\triangle$ SLA with typical amplitudes of $0.1 \mathrm{~m}$ and timescales of 2-4 weeks coincides with the variability in transport, which has an amplitude of about $0.5 \mathrm{~Sv}$.

Linear regression gives $Q=k \Delta \mathrm{SLA}+Q_{0}$, where $k=$ $6.5 \mathrm{~Sv} \mathrm{~m}^{-1}$. A sea level difference of $0.1 \mathrm{~m}$ between these two points, located $145 \mathrm{~km}$ apart, would give a mean barotropic current of about $0.05 \mathrm{~m} \mathrm{~s}^{-1}$, roughly corresponding to a change in transport across the sill of the order of $0.15 \mathrm{~Sv}$ (assuming a cross-sectional area for the overflow of about $15 \mathrm{~km} \times 200 \mathrm{~m}$ ). The sensitivity obtained by regressing $\triangle$ SLA against $Q$ is 4 times higher (an increase in $\triangle$ SLA of $0.1 \mathrm{~m}$ corresponds to an increase in $Q$ of $0.65 \mathrm{~Sv}$ ); that is, the responses in transport to changes in SLA gradients are stronger than what is expected from the addition of the barotropic component deduced from the SLA gradient. It is possible that (a) the barotropic current is more focused and thus stronger in the sill region than above the slope and/or (b) that there are changes in the plume thickness and baroclinic velocity associated with the changes in the SLA gradient. Indeed, the agreement in sensitivity between $\triangle$ SLA and $Q$ for points located more directly across the sill is better (with a factor of 2), and it was shown above that the plume thickness and transport co-vary. Note that with the kinematic definition of plume thickness used in the estimate of $Q$ from FB, changes in the barotropic component of the flow would not only influence the overflow velocity, but also the plume thickness. For the mean velocity profile from FB, the increase in kinematic interface height caused by a barotropic current of $0.1 \mathrm{~m} \mathrm{~s}^{-1}$ is $6 \mathrm{~m}$, or approximately $3 \%$ of the typical plume thickness.

\section{Discussion}

Recent results from a semi-idealized numerical model suggest that the eddies or oscillation observed downstream of the FBC sill are caused by growing baroclinic instabilities on the deeper edge of the dense plume (Guo et al., 2014). Baroclinic stability analysis of a parabolically shaped plume on a sloping bottom using the code developed by Reszka et al. (2002) and parameters (depth $=900 \mathrm{~m}$, density anomaly $0.41 \mathrm{~kg} \mathrm{~m}^{3}$, buoyancy frequency $N^{2}=8.12 \times 10^{-7} \mathrm{~s}^{-2}$ and slope $s=$ 0.01) relevant for the FBC overflow (Guo et al., 2014) shows that the period and wavelength of the most unstable wave decrease and the growth rate increases with increasing plume thickness (Fig. 10a). These results are in agreement with the observations presented in Sect. 3. The oscillation period decreases for increasing transport across the sill and a thicker plume and, while there are exceptions, the EKE tends to be high when the plume is thick and the volume transport is large (e.g. August and April), and low when the plume is thin and the volume flux is low (e.g. November).

The same tendency is seen in the results from the realistically forced numerical model (Fig. 4) and in the idealized experiments of Guo et al. (2014). The dominant period and the transport across the sill for the five sensitivity runs discussed in Guo et al. (2014) are included in Fig. 6. Note that the forcing, and thus the transport and also the oscillation period, is quasi-constant for each of the runs. The sensitivity in the oscillation period to changes in transport in these highly idealized model runs (forced solely by a dense inflow through the Faroe Shetland Channel, FSC, on the northern boundary) is much smaller $\left(-0.6\right.$ days $\left.\mathrm{Sv}^{-1}\right)$ than in the observations and in the more realistic model set-up described in this paper. Why is the oscillation period in the idealized 


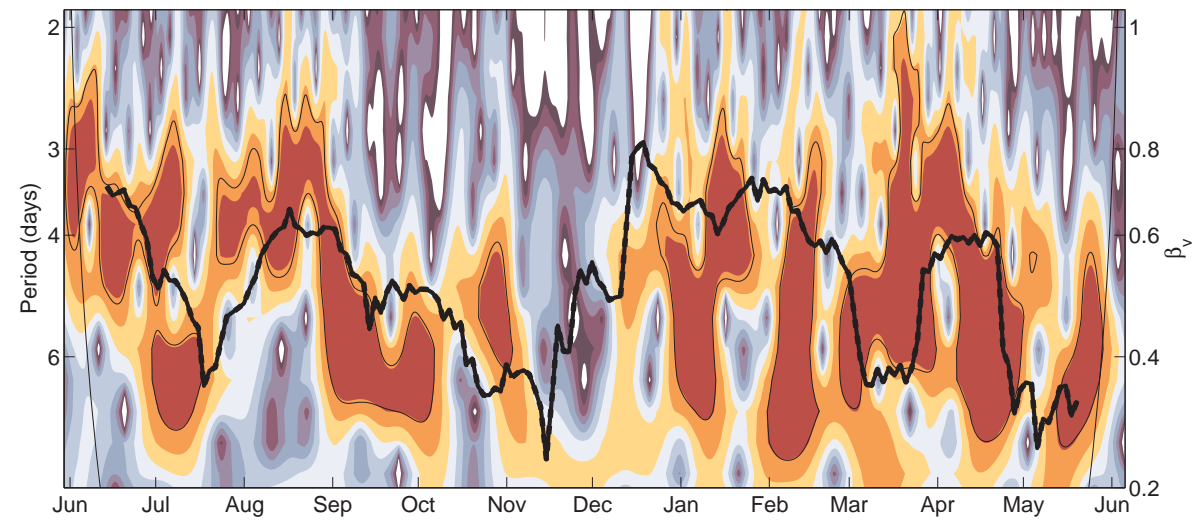

Figure 11. Time series of $\beta_{v}=\mathrm{EKE}_{v} / \mathrm{EKE}$ (thick, black line) superimposed onto a wavelet diagram from $\mathrm{S} 3$ (same as shown in Fig. 3d). Red colours indicate high energy and the thin, black line is the $95 \%$ significance level.

model runs much less sensitive to the overflow transport than the observations and the realistic modelling?

One possible reason is that the transport variability in the observations and the realistic model is linked to changes in the background circulation (see Fig. 9), whereas the increased flux in the idealized model is due solely to an increased baroclinic component. In addition, the observations and the realistic model show a velocity shear across the channel in the sill region within the upper layer (Fig. 7) that is absent in the idealized model. This shear is likely to be of barotropic origin since the upper layer is relatively homogenous across the channel. A barotropic shear can modify the disturbances generated by the baroclinic instability (Pedlosky, 1986, p. 582-589 in).

A barotropic component of the background current that is aligned with the overflow increases the transport of dense water across the sill, thus altering the conditions for baroclinic instability downstream and the intrinsic period of the most unstable wave. At the same time, the period observed at a stationary mooring is affected, since $T_{\mathrm{obs}}=\lambda /(c+v)$, where $\lambda$ is the wavelength, $c$ the phase velocity and $v$ the component of the background current that is aligned with the phase velocity. $T_{\text {obs }}$ decreases if the mean flow is in the direction of the phase speed of the wave and increases if the current is oppositely directed (see Fig. 10c). Throughout the year, the modelled upper layer velocity in the along-slope direction at $\mathrm{M}$ increases from nil to $u_{\text {up }}=0.1 \mathrm{~m} \mathrm{~s}^{-1}$ (Fig. 4f), and for a typical wavelength-wave number pair obtained from the instability analysis (Reszka et al., 2002; Guo et al., 2014), the corresponding reduction in the observed periodicity would be about 1 day (Fig. 10c), possibly explaining most of the variability in the period in the model results (Fig. 4d). To differentiate between advective effects and changes in the intrinsic periods of the generated instabilities, we turn to the underlying equations.

The results by Reszka et al. (2002) suggest that baroclinic instabilities appear as an amplifying topographic Rossby wave (TRW) in the upper layer of a two-layer flow with a continuously stratified upper layer. Marques et al. (2014) have shown that TRWs can be generated by dense overflows and their model study showed that the TRW properties varied in time, depending on factors including the background background current and the density of the overflow. The observations from the FBC overflow plume described in Darelius et al. (2011) and Darelius et al. (2013) are consistent with TRWs. For such waves, and for the parameters relevant in the FBC (Darelius et al., 2011), the dispersion relation is given by $\omega=s N \sin \alpha$, where $s=0.01$ is the slope, $N=3 \times 10^{-3} \mathrm{~s}^{-1}$ the average buoyancy frequency in the deepest $400 \mathrm{~m}$, and $\alpha$ the angle of the wave-number vector from down-slope (Rhines, 1970). An estimate of $\alpha$ can be obtained from the principal axis of the motion, which is normal to the wave-number vector if all the variance in the velocity is caused by the wave motion. According to the dispersion relation, the transverse motions of the waves change from along-slope orientation for low-frequency waves to increasingly cross-slope orientation at higher frequencies (Pickart and Watts, 1990). We would thus expect the fraction of the EKE in the cross-slope component, $\beta_{v}=\mathrm{EKE}_{v} / \mathrm{EKE}$, to decrease during time periods with a longer oscillation period and increase with a shorter oscillation period. Changes in the observed period due to advection by a background current would not influence $\beta_{v}$. The time series of $\beta_{v}$ is calculated from levels above the plume at S3 and shown in Fig. 11. Consistent with theory, the observational data show a tendency for low values of $\beta_{v}$ during time periods with longer oscillations, e.g. in November and May. The same relationship is found in the model data (not shown). This suggests that the baroclinic instabilities are indeed manifested as TRWs and that a part of the variability in the observed oscillation period is caused by changes in the properties (wavelength, intrinsic period) of the generated eddies. Advective effects caused by a variable background current may contribute to the observed variability in periodicity. The two processes are not 


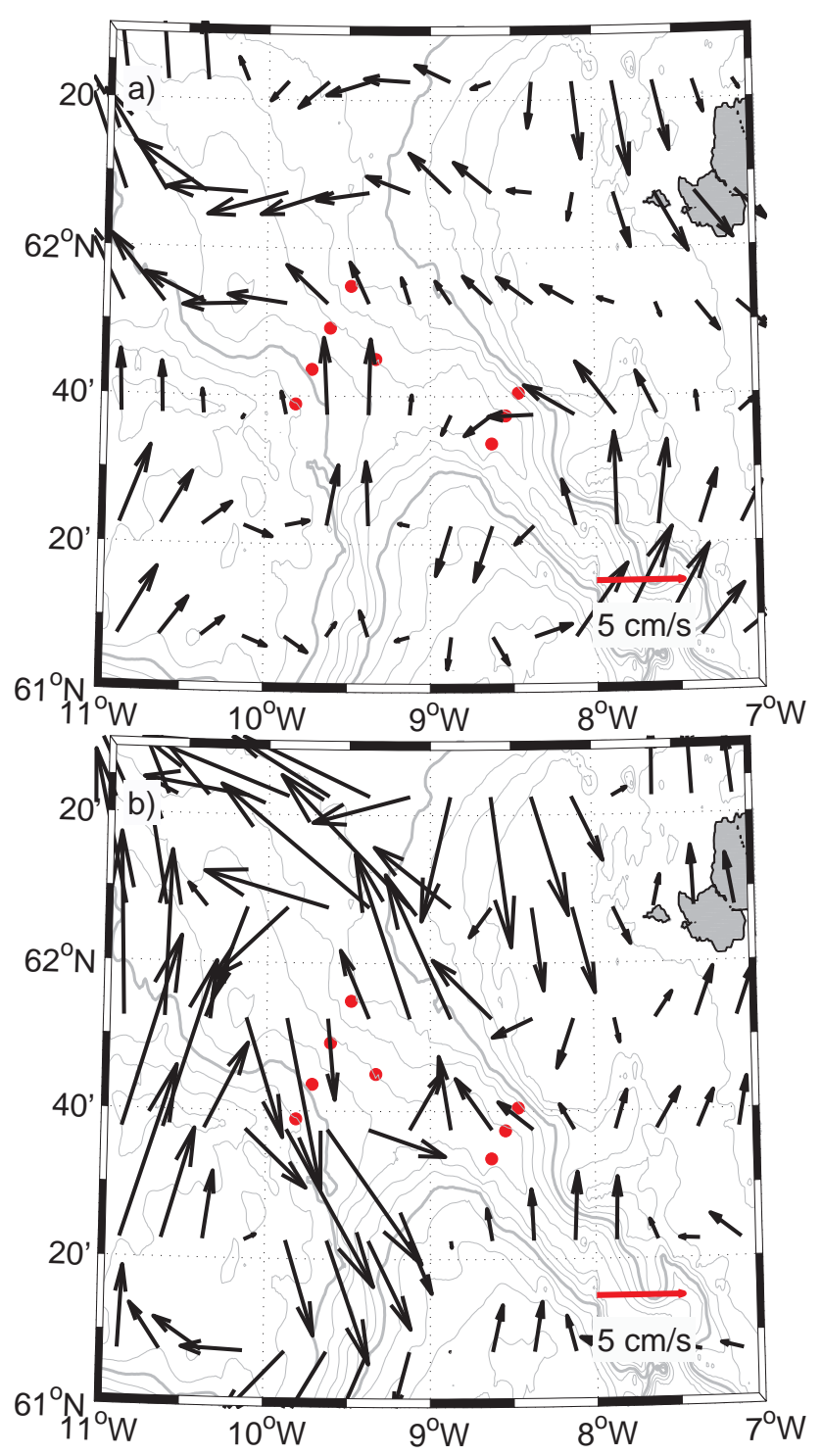

Figure 12. Mean geostrophic velocity anomaly (from AVISO) during the period (a) 1-31 May 2008 and (b) 3-10 June 2008. The red dots mark the positions of the moorings deployed in 2012-2013.

independent, since the background current is shown to be directly linked to the overflow transport and thus indirectly to the oscillation period.

Our results are consistent with previous observations. The regular oscillations observed by Geyer et al. (2006) change character towards the end of their measurement period; in October the period increases from $88 \mathrm{~h}$ to more than 5 days and towards the very end of the record the oscillations seemingly disappear (see their Fig. 9). The disappearance coincides with a relatively strong geostrophic velocity anomaly directed towards the sill (inferred from AVISO; not shown). In a similar manner, the oscillations on the slope change character in the beginning of June 2008, as discussed by Darelius et al. (2011). This occurs when the geostrophic velocity anomaly (inferred from AVISO) changes from being mainly aligned with the dense overflow (Fig. 12a) to a situation with relatively strong south-eastward flow above the lower part of the slope (Fig. 12b). Here, we show that the changing oscillations on the slope in 2012-2013 are associated with inflow anomalies above the overflow at the sill (Fig. 5d); similar (but weaker) anomalies are observed at the FB in October and November 1999 and in June 2008, when the oscillations observed by Geyer et al. (2006) and Darelius et al. (2011), respectively, change character.

The inflow in the upper layer on the Faroe Bank side is generally weaker in the numerical model, and strong inflow (weak overflow) events apparent in the sill moorings (e.g. in November-December 2008; not shown) are absent or only weakly represented in the model. The large fluctuations in transport observed at the sill ( $>1 \mathrm{~Sv}$ change over the course of a month) are thus not captured in the numerical model where the transport varies smoothly over the year. As a consequence, the oscillation period - shown in the observations to be strongly linked to the overflow transport - varies relatively smoothly in the model compared with the observations (compare Figs. $4 \mathrm{~d}$ and $3 \mathrm{~d}$ ). Although less variable, the relation between transport and oscillation period is the same in the model and the observations (Fig. 6), suggesting that the mechanism linking them together is well represented in the model although the large-scale background forcing determining the overflow transport is not. The variability in overflow transport and the transport itself is much too low in the model. The lack of variability in the model is likely related to the nesting approach. Large-scale features influencing the overflow that are missing in the coarser large-scale model providing the boundary conditions will be missing also in the regional, high-resolution run. A comparison of SSH variability obtained from satellite altimetry and model output shows that the variability in SSH gradients is relatively well represented in the model, although extreme values are typically $20-30 \%$ lower. The link between SSH gradients and overflow transport that is prominent in the observations, is missing in the model. The results from the model highlight the interplay between processes occurring at different spatial and temporal scales. To correctly model the eddy generation within the overflow, larger-scale processes and variability must be correctly represented.

The observations presented here support the conclusion by Guo et al. (2014) that the observed oscillations are caused by growing baroclinic instabilities. Our observations rule out several other candidate mechanisms that can play a role in generation of mesoscale variability at the timescales of interest. It has been suggested that variability in velocity records with similar timescales in mooring records from the southwestern slope of the FSC (Hosegood and Haren, 2004) would be linked to the local wind forcing and the generation of continental shelf waves (Hosegood and Haren, 2006; Gordon and Huthnance, 1987). Analysis of wind data from a weather station in Torshavn shows no spectral peak around in the 2- 


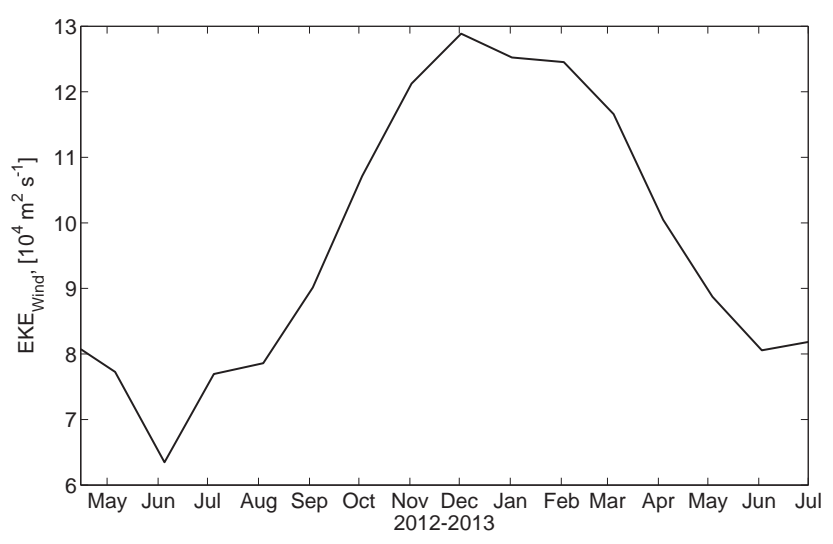

Figure 13. Time series of EKE in the 2-6-day band from wind observations in Torshavn (Cappelen, 2014) during 2012-2013.

6-day timescales (not shown). The wind EKE in the 2-6-day band (Fig. 13) shows a maximum in winter (when EKE in the mooring data is low) and a minimum in summer (when EKE in the mooring data is high) indicating that the observed variability in the plume region is not atmospherically forced. There is no difference between summer and winter in the prevailing wind direction during strong (wind speed exceeding $10 \mathrm{~m} \mathrm{~s}^{-1}$ ) wind events that otherwise could have caused a different oceanic response. Therefore, we conclude that the observed oscillations are not atmospherically driven. There are examples of topographic waves trapped around islands (see e.g. Brink, 1999), but an analysis of mooring records from the Nordic WOCE (World Ocean Circulation Experiment) mooring arrays surrounding the Faroe Islands does not show the presence of such waves in the frequency range observed here (Hátún, 2004). An inspection of the numerical model fields does not reveal such waves either.

\section{Conclusions}

Observations from the plume region downstream of the FBC sill typically show quasi-regular oscillations associated with dense domes of overflow water moving along the IcelandFaroe slope. The first year-long mooring records from the area reveal variability in the strength and periodicity of the oscillations that are directly linked to the variability in the volume transport of dense water across the sill of the FBC. In agreement with results from the baroclinic instability theory, the oscillations are more intense with a shorter period when the volume transport and the plume thickness increase. The intra-seasonal variability in the transport across the sill is shown to be linked to variability in local SSH gradient. It is shown that part of the variability (order 1 day) in the observed oscillation period can be explained by advective effects (due to a background barotropic current), but changes in the fraction of the EKE that is caused by across-isobath motion suggest changes in the intrinsic periodicity of the generated instabilities. The energetic, short-period oscillations are more efficient than the long-period oscillations in spreading the dense water on the slope, both to shallower and greater depths. While our understanding of the influence of eddy generation on plume mixing and entrainment is far from complete, the findings provide a link between overflow transport and eddy properties that can be invoked in a parametrization of overflow mixing. As a first step, future observational programs ought to be designed in order to test whether the relationship is transferable to other overflow regions.

Author contributions. E. Darelius and I. Fer designed and carried out the field campaign, T. Rasmussen set up and run the regional model, C. Guo provided results from the idealized model and K. M. H. Larsen provided the data from FB and did the transport calculation from FB. E. Darelius analysed the data and prepared the manuscript with contributions from all co-authors.

Acknowledgements. The authors are thankful to $\mathrm{H}$. Bryhni, S. Myking and the crew of R/V Håkon Mosby for help and assistance during mooring deployment and recovery. This work was funded by the Research Council of Norway through the FRINAT programme, under project no. 204867/V30 "Faroe Bank Channel Overflow: Dynamics and Mixing”. Discussions and suggestions from J. Ullgren, P. E. Isachsen, K. A. Orvik and B. Hansen are highly appreciated. The FB mooring was funded through the European Union 7th Framework Programme (FP7 2007-2013), under grant agreement no. 308299 NACLIM.

Edited by: M. Hecht

\section{References}

Amante, C. and Eakins, B. W.: ETOPO1 1 Arc-Minute Global Relief Model: Procedures, Data Sources and Analysis, Tech. rep., NOAA, technical memorandum NESDIS NGDC-24, 19 pp., 2009.

Bishop, S. P., Watts, D. R., and Donohue, K. A.: Divergent eddy heat fluxes in the Kuroshio extension at $144^{\circ}-148^{\circ} \mathrm{E}$. Part I: Mean structure, J. Phys. Oceanogr., 43, 1533-1550, doi:10.1175/JPO-D-12-0221.1, 2013.

Bleck, R.: An oceanic general circulation model framed in hybrid isopycnic-Cartesian coordinates, Ocean Model., 37, 55-88, 2002.

Brink, K. H.: Island-trapped waves, with application to observations off Bermuda, Dynam. Atmos. Oceans, 29, 93-118, doi:10.1016/S0377-0265(99)00003-2, 1999.

Cappelen, J.: Technical Report 14-09: Weather observations from Tórshavn, The Faroe Islands, Tech. rep., Danish Meterological Institute, Copenhagen, available at: http://www.dmi.dk/ fileadmin/Rapporter/TR/tr14-09, 2014.

Chassignet, E. P., Hurlburt, H. E., Smedstad, O. M., Halliwel, G. R., Hogan, P. J., Wallcraft, A. J., Baraille, R., and Bleck, R.: The HYCOM (HYbrid Coordinate Ocean Model) data assimilative system, J. Marine Syst., 65, 60-83, 2007. 
Darelius, E., Smedsrud, L. H., Østerhus, S., Foldvik, A., and Gammelsrød, T.: Structure and variability of the Filchner overflow plume, Tellus A, 61, 446-464, doi:10.1111/j.16000870.2009.00391.x, 2009.

Darelius, E., Fer, I., and Quadfasel, D.: Faroe Bank Channel overflow: mesoscale variability, J. Phys. Oceanogr., 41, 2137-2154, doi:10.1175/JPO-D-11-035.1, 2011.

Darelius, E., Ullgren, J. E., and Fer, I.: Observations of barotropic oscillations and their influence on mixing in the Faroe Bank Channel overflow region, J. Phys. Oceanogr., 43, 1525-1532, doi:10.1175/JPO-D-13-059.1, 2013.

Dee, D. P., Uppala, S. M., Simmons, A. J., Berrisford, P., Poli, P., Kobayashi, S., Andrae, U., Balmaseda, M. A., Balsamo, G., Bauer, P., Bechtold, P., Beljaars, A. C. M., van de Berg, L., Bidlot, J., Bormann, N., Delsol, C., Dragani, R., Fuentes, M., Geer, A. J., Haimberger, L., Healy, S. B., Hersbach, H., Hólm, E. V., Isaksen, L., Kållberg, P., Köhler, M., Matricardi, M., McNally, A. P., Monge-Sanz, B. M., Morcrette, J.-J., Park, B.K., Peubey, C., de Rosnay, P., Tavolato, C., Thépaut, J.-N., and Vitart, F.: The ERA-Interim reanalysis: configuration and performance of the data assimilation system, Q. J. Roy. Meteor. Soc., 137, 553-597, doi:10.1002/qj.828, 2011.

Dickson, R. R. and Brown, J.: The production of North Atlantic deep water, sources, rates, and pathways, J. Geophys. Res., 99, 12319-12341, doi:10.1029/94JC00530, 1994.

Fer, I., Voet, G., Seim, K. S., Rudels, B., and Latarius, K.: Intense mixing of the Faroe Bank Channel overflow, Geophys. Res. Lett., 37, L02604, doi:10.1029/2009GL041924, 2010.

Geyer, F., Østerhus, S., Hansen, B., and Quadfasel, D.: Observations of highly regular oscillations in the overflow plume downstream of the Faroe Bank Channel, J. Geophys. Res., 111, 1-11, doi:10.1029/2006JC003693, 2006.

Gordon, R. L. and Huthnance, J.: Storm-driven continental shelf waves over the Scottish continental shelf, Cont. Shelf Res., 7, 1015-1048, 1987.

Guo, C., Ilicak, M., Fer, I., Darelius, E., and Bentsen, M.: Baroclinic instability of the Faroe Bank Channel overflow, J. Phys. Oceanogr., 44, 2698-2717, doi:10.1175/JPO-D-14-0080.1, 2014

Hansen, B. and Østerhus, S.: Faroe Bank Channel overflow 19952005, Prog. Oceanogr., 75, 817-856, 2007.

Hansen, B., Turrell, W. R., and Østerhus, S.: Decreasing overflow from the Nordic seas into the Atlantic Ocean through the Faroe Bank Channel since 1950, Nature, 411, 927-930, 2001.

Hansen, B., Østerhus, S., Hátún, H., Kristiansen, R., and Larsen, K.: The Iceland-Faroe inflow of Atlantic water to the Nordic Seas, Prog. Ocean., 59, 443-474, doi:10.1016/j.pocean.2003.10.003, 2003.

Hosegood, P. and Haren, H. V.: Near-bed solibores over the continental slope in the Faeroe-Shetland Channel, Deep-Sea Res. Pt. II, 51, 2943-2971, doi:10.1016/j.dsr2.2004.09.016, 2004.

Hosegood, P. and Haren, H. V.: Sub-inertial modulation of semi-diurnal currents over the continental slope in the Faeroe-Shetland Channel, Deep-Sea Res, Pt. I, 53, 627-655, doi:10.1016/j.dsr.2005.12.016, 2006.

Høyer, J. L. and Quadfasel, D.: Detection of deep overflows with satellite altimetry, Geophys. Res. Lett., 28, 1611-1614, 2001.

Hátún, H.: The Faroe Current (PhD thesis), Tech. rep., University of Bergen, Bergen, 2004.
Krauss, W. and Käse, R. H.: Eddy formation in the Denmark Strait overflow, J. Geophys. Res.-Oceans, 103, 15525-15538, 1998.

Large, W. G., McWilliams, J. C., and Doney, S. C.: Oceanic vertical mixing: a review and a model with a nonlocal boundary layer parametrization, Rev. Geophys., 32, 363-403, 1994.

Larsen, K. M. H., Hatun, H., Hansen, B., and Kristiansen, R.: Atlantic water in the Faroe area: sources and varibility, ICES J. Mar. Sci., 69, 802-808, 2012.

Marques, G. M., Padman, L., Springer, S. R., Howard, S. L., and Özgökmen, T. M.: Topographic vorticity waves forced by Antarctic dense shelf water outflows, Geophys. Res. Lett., 41, 1247-1254, doi:10.1002/2013GL059153, 2014.

Mauritzen, C., Price, J., Sanford, T., and Torres, D.: Circulation and mixing in the Faroese Channels, Deep-Sea Res. Pt. I, 52, 883 913, doi:10.1016/j.dsr.2004.11.018, 2005.

Miller, A. J., Lermusiaux, P. F. J., and Poulain, P.-M.: A topographic-Rossby mode resonance over the IcelandFaeroe Ridge, J. Phys. Oceanogr., doi:10.1175/15200485(1996)026<2735:ATMROT>2.0.CO;2, 1996.

Mysak, L. A. and Schott, F.: Evidence for baroclinic instability of the Norwegian current, J. Geophys. Res., 82, 2087, doi:10.1029/JC082i015p02087, 1977.

Pedlosky, J.: Geophysical Fluid Dynamics, Springer Verlag, 2nd ed. edn., 1986.

Pickart, R. S. and Watts, D. R.: Deep western boundary current variability at Cape Hatteras, J. Mar. Res., 48, 765-791, doi:10.1357/002224090784988674, 1990.

Rasmussen, T. A., Olsen, S. M., Hansen, B., Hátún, H., and Larsen, K. M.: The Faroe shelf circulation and its potential impact on the primary production, Cont. Shelf Res., 88, 171-184, doi:10.1016/j.csr.2014.07.014, 2014.

Reszka, M. K., Swaters, G. E., and Sutherland, B. R.: Instability of abyssal currents in a continuously stratified ocean with bottom topography, J. Phys. Oceanogr., 32, 3528-3550, 2002.

Rhines, P. B.: Edge-, bottom-, and Rossby waves in a rotating stratified fluid, J. Fluid Mech., 69, 273-302, 1970.

Ribergaard, M. H.: Scientific Report 11-02: Ensemble oil drift modelling for bottom spill off Southwest Greenland, Tech. rep., Danish Meteorological Institute, Copenhagen, Denmark, available at: http://www.dmi.dk/fileadmin/Rapporter/SR/sr11-02.pdf, 2012.

Seim, K. S., Fer, I., and Berntsen, J.: Regional simulations of the Faroe Bank Channel overflow using a $\sigma$-coordinate ocean model, Ocean Model., 35, 31-44, doi:10.1016/j.ocemod.2010.06.002, 2010.

Simonsen, K., Larsen, K. M. H., Mortensen, L., and Norbye, A. M.: New Bathymetry for the Faroe Shelf, Tech. rep., Faculty of Science and Technology, University of the Faroe Islands, 2002.

Skagseth, $\varnothing$. and Orvik, K. A.: Identifying fluctuations in the Norwegian Atlantic slope current by means of empirical orthogonal functions, Cont. Shelf Res., 22, 547-563, doi:10.1016/S02784343(01)00086-3, 2002.

Torrence, C. and Compo, G. P.: A practical guide to wavelet analysis, B. Am. Meteorol. Soc., 79, 61-78, doi:10.1175/15200477(1998)079<0061:APGTWA>2.0.CO;2, 1997.

Ullgren, J. E., Darelius, E., and Fer, I.: Volume transport and mixing of the Faroe Bank Channel overflow from one year of moored measurements, Ocean Sci. Discuss., 12, 2315-2359, doi:10.5194/osd-12-2315-2015, 2015. 
Voet, G. and Quadfasel, D.: Entrainment in the Denmark Strait overflow plume by meso-scale eddies, Ocean Sci., 6, 301-310, doi:10.5194/os-6-301-2010, 2010. 